Research Paper

\title{
Chronic hepatitis $B$ virus infection is associated with a poorer prognosis in diffuse large B-cell lymphoma: a meta-analysis and systemic review
}

Xingyu Rong1,2\#, Hai Wang1,2\#, Jiexian Ma2\#, Shaokun Pan1, Huijing Wang2,3凶, Sha Jing1,4, Yu Su1, Lancui Wang ${ }^{1}$, Chao Zhao ${ }^{1,2,4}$

1. MOE/NHC/CAMS Key Lab of Medical Molecular Virology, School of Basic Medical Sciences \& National Clinical Research Center for Aging and Medicine, Huashan Hospital, Fudan University, Shanghai, 200032, P.R. China

2. Shanghai Key Laboratory of Clinical Geriatric Medicine, Huadong Hospital, Shanghai, 200040, P.R. China

3. Laboratory of Neuropsychopharmacology, College of Fundamental Medicine, Shanghai University of Medicine \& Health Science, 201318, P.R. China

4. Institute for Basic Research on Aging and Medicine, School of Basic Medical Sciences, Shanghai Medical College of Fudan University, Shanghai, 200032, P.R. China.

\#These authors contributed equally.

$\square$ Corresponding author: Dr Zhao C Phone (Fax): +86-021-54237602 E-mail: czhao@fudan.edu.cn Address: MOE/NHC/CAMS Key Lab of Medical Molecular Virology, School of Basic Medical Sciences \& National Clinical Research Center for Aging and Medicine, Huashan Hospital, Fudan University, Shanghai, 200032, P.R. China; Or Dr Wang HJ Phone (Fax): +86-021-65882769 E-mail: wanghj@sumhs.edu.cn Address: Laboratory of Neuropsychopharmacology, College of Fundamental Medicine, Shanghai University of Medicine \& Health Science, 201318, P.R. China.

(c) Ivyspring International Publisher. This is an open access article distributed under the terms of the Creative Commons Attribution (CC BY-NC) license (https:// creativecommons.org/licenses/by-nc/4.0/). See http://ivyspring.com/terms for full terms and conditions.

Received: 2018.10.28; Accepted: 2019.05.06; Published: 2019.06.09

\begin{abstract}
Accumulating evidence from clinical trials indicates chronic hepatitis $B$ virus (HBV) infection is associated with the incidence of diffuse large $B$-cell lymphoma (DLBCL) and may be associated with the prognosis of $\mathrm{DLBCL}$, though this suggestion remains controversial. We performed a meta-analysis to assess whether HBV infection is associated with prognosis and response to chemotherapy in DLBCL. After a strict literature search strategy, a total of $809 \mathrm{HBV}$ surface antigen $(\mathrm{HBsAg})$ seropositive patients with $\mathrm{DLBCL}$ and $2849 \mathrm{HBsAg}$ seronegative patients with DLBCL from twelve trials were included. DLBCL patients with chronic HBV infection had significantly poorer 2- and 5-year overall survival (OS) (HR 1.54, 95\% Cl 1.23-1.92, $P<0.001$ and 1.79, 1.48-2.17, $P<0.001$ ) and 2- and 5-year progression-free survival (PFS) (HR 1.44, 95\% Cl 1.14-1.81, $P=0.002$ and HR 1.34, 95\% Cl 1.02-1.75, $P=0.03)$. HBsAg-seronegative patients also had a lower complete response $(C R)$ rate $(O R 0.48,95 \% \mathrm{Cl} 0.34-0.68, P<0.001)$, higher progressive disease $(P D)$ rate (OR $2.08,95 \% \mathrm{Cl} 1.34-3.24, P=0.001)$, and more advanced clinical features. This meta-analysis indicates $\mathrm{HBV}$ infection leads to a poorer prognosis and poorer response to standard chemotherapy.
\end{abstract}

Key words: Hepatitis B virus; Diffuse Large B Cell Lymphoma; Prognosis; Clinical outcome;Systematic review

\section{Introduction}

Diffuse large B-cell lymphoma (DLBCL), the most common type of non-Hodgkin lymphoma (NHL), accounts for $30-40 \%$ of adult cases of NHL. Although significant developments and progress have been made in the treatment of aggressive lymphoma in recent decades, $40 \%$ of patients with DLBCL still die of disease recurrence [1].

A number of clinical trials have found that hepatitis B virus (HBV) infection may lead to a poorer prognosis and response to standard chemotherapy in DLBCL; however, these results are controversial. Overall survival (OS) and progression free survival (PFS) have mainly been used to evaluate prognosis in DLBCL. Deng, Guo and Shan reported that HBV infection may lead to poorer OS [2-4], while Law and Zhang reported the opposite result. However, many researchers use different criteria to evaluate PFS [5, 6]. The rates of complete response $(\mathrm{CR})$ and progressive 
disease (PD) can more objectively reflect the response of patients to standard chemotherapy [1]. Most related studies have not indicated a significant positive relationship between $\mathrm{HBV}$ infection and the response to standard chemotherapy in patients with DLBCL [3-5, 7, 8]. However, Deng and Feng demonstrated HBV infection negatively affected the response to chemotherapy $[2,9]$. Additionally, while the clinical outcomes of patients with DLBCL can be predicted using other indices, such as the International Prognostic Index (IPI), serum lactate dehydrogenase $(\mathrm{LDH})$ and the presence of $\mathrm{B}$ symptoms, these indices have not been consistently identified as prognostic factors across all studies.

There are estimated to be more than 350 million carriers of persistent HBV worldwide, one third of who develop serious sequelae such as cirrhosis, liver failure and hepatocellular carcinoma (HCC). The increased risk of malignant changes is a serious threat to the health of HBV carriers [10]. Therefore, the relationship between HBV infection and the prognosis of DLBCL is an important issue, especially in Asian-Pacific regions where the prevalence of $\mathrm{HBV}$ is high.

Further assessment of the relationship between chronic HBV infection and DLBCL may contribute to our knowledge on the pathogenesis of DLBCL, and more importantly, indicate the importance of anti-viral treatment in $\mathrm{HBV}$-infected patients with DLBCL. Thus, we conducted a meta-analysis to explore the relationship between HBV infection and disease progression in DLBCL.

\section{Methods}

\section{Inclusion and exclusion criteria}

Randomized controlled trials and retrospective studies published up to February 2019 were included in this meta-analysis if they focused on the prognosis or other clinical indices of DLBCL among patients with or without chronic HBV infection. DLBCL had to be diagnosed by cytological examination or pathological examination according to the World Health Organization (WHO) Classification of Tumors of Hematopoietic and Lymphoid Tissues [1]. DLBCL was clinically staged according to the Ann Arbor staging criteria [11]. Chronic HBV infection was defined as serum HBV surface antigen (HBsAg) positivity above the baseline. The risks were reported or calculated from the primary data as OR with corresponding 95\% CIs. The quality of all included studies was evaluated using the Newcastle-Ottawa Scale (NOS) [12]. Studies with the NOS of 5 or less were excluded for further analysis. Disagreements were resolved by discussion between the two investigators (X.R. and H.W.).

\section{Literature search strategy}

A systemic review was conducted by strictly following the Meta-Analysis of Observational Studies in Epidemiology (MOOSE) guidelines for reporting of systematic review and meta-analysis [13]. We carried out literature searches of the PubMed, EMBASE and Cochrane Central Register of Controlled Trials (CENTRAL/CCTR) databases and Chinese databases including WANFANG, CNKI and VIP. We used the keywords "HBV", "HBsAg", "Hepatitis B", "Hepatitis B virus", "Dane particle" AND "DLBCL", "Diffuse Large B cell lymphoma". The specific literature search strategy is listed in Table 1. Two authors (X.R. and H.W.) independently screened all retrieved titles and abstracts and selected studies for further screening. Disagreements were resolved by discussion between the two investigators.

\section{Data extraction}

Two authors (X.R. and H.W.) independently extracted the data from the included trials. We identified the trials using the name of the first author and the year in which the trial was first published. We extracted data on the outcomes of HBsAg-positive and -negative patients. In order to confirm that each trial met the inclusion criteria for this meta-analysis, data on the assessment and treatment of DLBCL and chronic HBV infection were also extracted from each study. Disagreements were resolved by discussion between the two investigators.

\section{Data analysis}

We used Engauge Digitizer 4.1 to calculate the 2-year and 5-year OS and PFS follow-up data from the published survival curves if the exact data was not given in the study. Revman Manager 5.3 was used to conduct the meta-analysis. Hazard ratios (HRs) were used to compare OS and PFS, and OR values and 95\% CIs were used to assess other indices. Inter-study heterogeneity was measured using the Chi-squared test and $\mathrm{I}^{2}$ metric with significance set at $P<0.1$ or $\mathrm{I}^{2}>$ $50 \%$. A fixed-effect model should be utilized in the absence of significance heterogeneity; otherwise a random-effect model should be applied. Sensitivity analyses were employed to determine if there was a possible source of heterogeneity. The $Z$ test was employed to assess the overall effect; $P$-values less than 0.05 were considered significant. Funnel plots were used to analyze publication bias.

\section{Results}

\section{Description of studies}

We conducted a strict literature search following the established search strategies. In total, 362 clinical 
trials, from 1977 so far, were retrieved after excluding duplications. Among them, 330 were excluded after screening the titles and abstracts, and 32 were evaluated in detail. And finally, only 15 trials from the first report in 2012 updating to February 2019 met the eligibility criteria for this meta-analysis. The flowchart summarizing the literature search is shown in Figure 1.

Table 1. Search strategy

\begin{tabular}{|c|c|c|}
\hline Database & Period & Search strategy \\
\hline PubMed & -2019.2 & $\begin{array}{l}\text { ((( "Lymphoma, Large B-Cell, Diffuse/epidemiology"[Mesh] OR "Lymphoma, Large B-Cell, Diffuse/etiology"[Mesh] OR "Lymphoma, Large } \\
\text { B-Cell, Diffuse/genetics"[Mesh] OR "Lymphoma, Large B-Cell, Diffuse/immunology"[Mesh] OR "Lymphoma, Large B-Cell, } \\
\text { Diffuse/microbiology"[Mesh] OR "Lymphoma, Large B-Cell, Diffuse/virology"[Mesh] ) AND (("HBV"[TIAB] OR "HBSAG"[TIAB] OR "Hepatitis } \\
\text { B"[TIAB] OR "Hepatitis B virus"[TIAB] OR "Dane Particle"[TIAB]) NOT Hemoglobin-vesicles[TIAB])) OR (( "Hepatitis B } \\
\text { virus/complications"[Mesh] OR "Hepatitis B virus/pathogenicity"[Mesh] ) OR ( "Hepatitis B, Chronic/complications"[Mesh] OR "Hepatitis B, } \\
\text { Chronic/epidemiology"[Mesh] ) OR ( "Hepatitis B/complications"[Mesh] OR "Hepatitis B/epidemiology"[Mesh] OR "Hepatitis } \\
\text { B/physiopathology"[Mesh] OR "Hepatitis B/statistics and numerical data"[Mesh] )) AND (“Diffuse”[TIAB] AND (“Large B-Cell”[TIAB] OR } \\
\text { "LARGE CELL" OR “B CELL") AND “Lymphoma”[TIAB])) OR (("Large B-Cell”[TIAB] OR “LARGE CELL" OR “B CELL”) AND } \\
\text { "Lymphoma”[TIAB]) AND (("HBV"[TIAB] OR "HBSAG"[TIAB] OR "Hepatitis B"[TIAB] OR "Hepatitis B virus"[TIAB] OR "Dane Particle"[TIAB]) } \\
\text { NOT Hemoglobin-vesicles[TIAB])) }\end{array}$ \\
\hline EMBASE & -2019.2 & $\begin{array}{l}\# 1 \text { exp hepatitis b/ or exp hepatitis b, chronic/ } \\
\text { \#2 exp Hepatitis B virus/ } \\
\# 3 \text { exp Lymphoma, Large B-Cell, Diffuse/ } \\
\text { \#4 (HBV or Hepatitis B or Hepatitis B virus).ti. } \\
\# 5 \text { (Diffuse and Large B-Cell and Lymphoma).ti. } \\
\# 6 \text { \#1 or \#2 } \\
\# 7 \# 5 \text { and \#6 } \\
\# 8 \# 3 \text { and \#4 } \\
\# 9 \text { \#4 and \#5 } \\
\# 10 \# 7 \text { or \#8 or \#9 }\end{array}$ \\
\hline $\begin{array}{l}\text { The Cochrane } \\
\text { Central } \\
\text { Register of } \\
\text { Controlled } \\
\text { Trials } \\
\text { (CENTRAL/ } \\
\text { CCTR) in The } \\
\text { Cochrane } \\
\text { Library }\end{array}$ & -2019.2 & $\begin{array}{l}\text { \#1 MeSH descriptor: [Hepatitis B] explode all trees } \\
\text { \#2 MeSH descriptor: [Hepatitis B virus] explode all trees } \\
\text { \#3 MeSH descriptor: [Lymphoma, Large B-Cell, Diffuse] explode all trees } \\
\text { \#4 Diffuse and ("Large B-Cell" or "LARGE CELL" or "B CELL") and *:ti,ab,kw (Word variations have been searched) } \\
\text { \#5 hbv or "hepatitis b" or "hepatitis b virus" or "hbsag":ti,ab,kw (Word variations have been searched) } \\
\# 6 \text { (\#1 or \#2) and \#4 } \\
\# 7 \text { \#3 and \#5 } \\
\# 8 \# 4 \text { and \#5 } \\
\# 9 \text { (\#6 or \#7 or \#8) }\end{array}$ \\
\hline
\end{tabular}

Records identified through database searching: PubMed $(\mathrm{n}=339)$

EMBASE $(\mathrm{n}=312)$

Chochrane Library $(n=11)$

WANGFANG DATA $(n=102)$

$\operatorname{VIP}$ DATA $(n=72)$

\begin{tabular}{|l|l|}
\hline & \\
\hline $\begin{array}{l}\text { Records after duplicates removed } \\
\mathrm{n}=362\end{array}$ \\
\hline
\end{tabular}

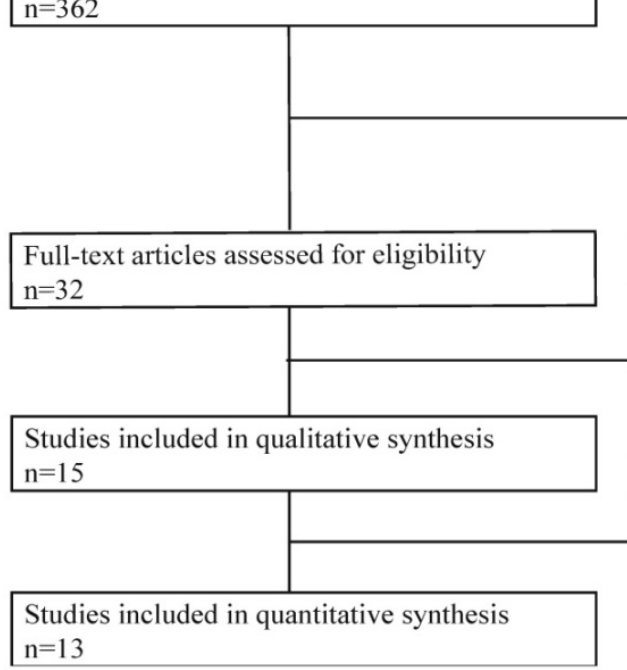

Records excluded

$\mathrm{n}=330$

Those records were not clinical trials or did not focus on the relationship between DLBCL and HBV infection.

17 of full-text articles excluded, with reasons

No specific data on the prognosis of HBV -associated DLBCL $n=14$

Without control group $n=2$

Occult hepatitis B virus $n=1$

Two were excluded due to its low quality.

Figure 1. Flow chart of literature screening and selection. 


\section{Quality Assessment}

The quality of all 15 eligible clinical trials was evaluated using the NOS. Thirteen trials were high quality (scores over 6) and one trial scored 6 (moderate quality). The remaining trials [14,15] with low quality (score of 5) were excluded from the meta-analysis. The specific details are shown in Table 2.

Table 2. Quality assessment for studies.

\begin{tabular}{|c|c|c|c|c|c|c|c|c|c|c|}
\hline \multirow[t]{3}{*}{ Study } & \multicolumn{9}{|c|}{ Quality indicators from Newcastle-Ottawa scale } & \multirow[t]{3}{*}{ Score } \\
\hline & \multicolumn{4}{|c|}{ Selection } & \multicolumn{2}{|c|}{ Comparability } & \multicolumn{3}{|c|}{ Exposure/Outcome } & \\
\hline & 1 & 2 & 3 & 4 & $5 a$ & $5 b$ & 6 & 7 & 8 & \\
\hline Chai 2016 & $\star$ & $\star$ & & $\star$ & $\star$ & & $\star$ & & & 5 \\
\hline Deng 2015 * & $\star$ & $\star$ & $\star$ & $\star$ & $\star$ & $\star$ & $\star$ & $\star$ & $\star$ & 9 \\
\hline Feng 2016 & $\star$ & $\star$ & & $\star$ & & $\star$ & $\star$ & $\star$ & $\star$ & 7 \\
\hline Guo 2015 * & $\star$ & $\star$ & $\star$ & $\star$ & $\star$ & $\star$ & $\star$ & $\star$ & $\star$ & 9 \\
\hline Guo 2018 & $\star$ & $\star$ & & $\star$ & $\star$ & $\star$ & $\star$ & $\star$ & $\star$ & 8 \\
\hline Huang 2012 & $\star$ & $\star$ & & $\star$ & $\star$ & $\star$ & $\star$ & $\star$ & & 7 \\
\hline Law 2015 & $\star$ & $\star$ & & $\star$ & $\star$ & $\star$ & $\star$ & $\star$ & $\star$ & 8 \\
\hline Pang 2018 & $\star$ & $\star$ & & $\star$ & $\star$ & & $\star$ & & & 5 \\
\hline Shan 2016 & $\star$ & $\star$ & & $\star$ & $\star$ & $\star$ & $\star$ & $\star$ & & 7 \\
\hline Wang 2016 & $\star$ & $\star$ & & $\star$ & & & $\star$ & $\star$ & $\star$ & 6 \\
\hline Wang 2018 & $\star$ & $\star$ & & $\star$ & $\star$ & & $\star$ & $\star$ & $\star$ & 7 \\
\hline Wei 2015 & $\star$ & $\star$ & & $\star$ & & $\star$ & $\star$ & $\star$ & $\star$ & 7 \\
\hline Wei 2014 & $\star$ & $\star$ & & $\star$ & $\star$ & $\star$ & $\star$ & $\star$ & & 7 \\
\hline Zhang 2012 & $\star$ & $\star$ & & $\star$ & $\star$ & $\star$ & $\star$ & $\star$ & $\star$ & 8 \\
\hline Zheng 2014 * & $\star$ & $\star$ & $\star$ & $\star$ & $\star$ & $\star$ & $\star$ & $\star$ & $\star$ & 9 \\
\hline
\end{tabular}

For case-control studies, 1 indicates that the case is definite with independent validation; 2 the case is consecutive or representative of population; 3 the control is from community; 4 the control is HBsAg seronegative; 5a study controls for receiving standard treatment; $5 \mathrm{~b}$ studies control for no HIV infection; 6 the case's exposure is ascertained by secure record or blinded-interview; 7 the ascertainmen for case and control are the same; 8 Non-Response rate of both group is same. For cohort studies $\left(^{*}\right)$ : For cohort studies, 1 indicates exposed cohort truly representative, 2 the non-exposed cohort drawn from the same hospital,3 ascertainment of exposure by secure record or structured interview, 4 outcome of interest was not present at start of study, 5a cohorts comparable on basis of all patients receiving standard treatment, $5 \mathrm{~b}$ study controls for no HIV infection, 6 quality of outcome assessment, 7 follow-ups long enough for outcomes to occur;8 complete follow-up.

\section{Characteristics of included studies}

The characteristics of the thirteen trials that qualified for this meta-analysis are listed in Table S1 $[2,3,5,6,8,9,16-22]$. Ten of the thirteen trials reported using the standard therapy for DLBCL of CHOP or R-CHOP. Therapy for HBV infection was only mentioned in three trials: Deng's (2015) [2], Guo's (2015) [3] and Law's studies (2015) [5].

\section{Chronic HBV infection and prognosis in DLBCL}

Compared to patients who did not have chronic HBV infection, DLBCL patients with chronic HBV infection had significantly poorer OS and PFS. For OS, the HR was 1.54 at 2 years (95\% CI 1.23-1.92, $P<0.001$, Figure 2A) and 1.79 at 5 years (95\% CI 1.48-2.17, $P<$ 0.001 , Figure 2B). For PFS, the HR was 1.44 at 2 years (95\% CI 1.14-1.81, $P=0.002$, Figure 2C) and 1.34 at 5 years $(95 \% \mathrm{CI} 1.02-1.75, P=0.03$, Figure $2 \mathrm{D})$.

\section{Chronic HBV infection and response to chemotherapy in DLBCL}

DLBCL patients with chronic HBV infection had a higher rate of PD than patients without chronic HBV infection (OR 2.08, 95\% CI 1.34-3.24, $P=0.001$, Figure 3B). DLBCL patients with chronic HBV infection also had a lower CR rate (OR 0.48, 95\% CI 0.34-0.68, $P$ $<0.001$, Figure 3A).

\section{Chronic HBV infection and the clinical features of DLBCL}

In the eleven trials that reported the age of onset of DLBCL, patients with chronic HBV infection were significantly younger when diagnosed with DLBCL than patients without chronic HBV infection (OR 2.19, 95\% CI 1.75-2.74, $P<0.001$, Figure 4 A), they were more likely to be diagnosed younger than 60-years-old. Patients with chronic HBV infection were also more likely to have advanced DLBCL (stage 3 or 4 ) at diagnosis (OR 1.85, 95\% CI 1.55-2.23, $P<0.001$, Figure $4 \mathrm{~B})$ and significantly more likely to have elevated LDH (OR 1.40, 95\% CI 1.14-1.73, $P=0.002$, Figure 4C).

However, there was no significant difference in having B symptom (OR 1.31, 95\% CI 0.71-2.42, $P=0.39$, Figure 4D), IPI score (IPI score $>2$ : OR $0.93,95 \%$ CI $0.62-1.41, P=0.74$, Figure $4 \mathrm{E}$ ) or the number of extra-nodal sites (more than one extra-nodal site vs. no sites or one extra-nodal site: OR 1.13, 95\% CI 0.88-1.44, $P=0.34$, Figure $4 \mathrm{~F}$ ) between DLBCL patients with and without chronic HBV infection. HBV infection was not associated with the subtype of DLBCL (non-GCB vs. GCB: OR 0.94, 95\% CI 0.48-1.83; $P=0.85$; Figure 4G). All the detailed results are listed in Table 3. Additionally, funnel plots were used to analyze publication bias of each comparison and the results were shown in Figure S1.

\section{Discussion}

This meta-analysis found that chronic HBV infection is associated with the prognosis of DLBCL. Patients with chronic HBV infection had significantly poorer 2-year and 5-year OS and PFS. Remarkably, DLBCL patients with HBsAg-seropositive also had poorer responses to standard chemotherapy, with a higher $\mathrm{PD}$ rate and lower $\mathrm{CR}$ rate, than their HBsAg-seronegative counterparts. Additionally, the patients with chronic HBV infection tended to be diagnosed with DLBCL at a younger age, had more advanced disease (stage 3 or 4) at diagnosis, and were more likely to have elevated LDH. However, there was no evidence that chronic HBV infection was related to the onset of $\mathrm{B}$ symptoms, IPI score, the number of extra-nodal sites or the subtype of DLBCL. 
A. Two-year OS

Study or Subgroup HBsAg seropositive HBsAg seronegative

\begin{tabular}{lrrrr} 
& Events & Total & Events & Total \\
\hline Deng 2015 & 43 & 81 & 152 & 506
\end{tabular}

Guo 2015

Guo 2018

Huang 2012

Law 2015

Shan 2016

Zhang 2012

$\begin{array}{lll}43 & 81 & 152\end{array}$

11

25

13

$7 \quad 31$

$4 \quad 16$

16
37

11

Total $(95 \% \mathrm{Cl})$

24

43

94

Total

Hazard Ratio

$\begin{array}{rrrr}12.52190257 & 23.19497691 & 30.6 \% & 1.72[1.14,2.58]\end{array}$

$\begin{array}{llllll}61 & 1.02607407 & 6.58017493 & 8.7 \% & 1.17[0.54,2.51]\end{array}$

$\begin{array}{llll}166 & 9.11446732 & 12.28898143 & 16.2 \%\end{array}$

$\begin{array}{llrr}118 & 1.27071636 & 3.29534706 & 4.3 \%\end{array}$

$2.10[1.20,3.67]$

$\begin{array}{lllll}61 & 2.56518516 & 6.58017493 & 8.7 \% & 1.48[0.69,3.17]\end{array}$

325

1144

$1.48[0.69,3.17]$
$1.20[0.77,1.88]$

143

Test for overall effect: $Z=3.74(P=0.0002)$

$100.0 \%$

B. Five-year OS

\begin{tabular}{ccccc} 
& \multicolumn{2}{c}{ HBsAg seropositive } & \multicolumn{2}{c}{ HBsAg seronegative } \\
Study or Subgroup & Events & Total & Events Total
\end{tabular}

\begin{tabular}{lrr} 
Study or Subgroup & Events & To \\
\hline Deng 2015 & 45 & \\
Feng 2016 & 12 \\
Guo 2015 & 25 \\
Guo 2018 & 62 \\
Huang 2012 & 7 \\
Law 2015 & 5 \\
Shan 2016 & 61 \\
Zhang 2012 & 41 \\
&
\end{tabular}

Total events
Heterogeneity: $\mathrm{Chi}^{2}=9.56, \mathrm{df}=7(\mathrm{P}=0.21) ; \mathrm{I}^{2}=27 \%$

Total events
Heterogeneity: $\mathrm{Chi}^{2}=9.56, \mathrm{df}=7(\mathrm{P}=0.21) ; \mathrm{I}^{2}=27 \%$

Total

Total O-E Variance Weight $\operatorname{Exp}[(0-\mathrm{E}) / \mathrm{V}]$, Fixed, 95\%

$1.54[1.23,1.92]$

Test for overall effect: $Z=6.04(P<0.00001)$

$\begin{array}{lllll}506 & 12.52190257 & 23.19497691 & 21.7 \% & 1.72[1.14,2.58]\end{array}$

$\begin{array}{lllll}116 & 1.02607407 & 6.58017493 & 6.2 \% & 1.17[0.54,2.51]\end{array}$

$\begin{array}{lllll}61 & 9.11446732 & 12.28898143 & 11.5 \% & 2.10[1.20,3.67]\end{array}$

$\begin{array}{lllll}166 & 1.27071636 & 3.29534706 & 3.1 \% & 1.47[0.50,4.33]\end{array}$

$\begin{array}{lllll}118 & 2.61681803 & 4.75537266 & 4.5 \% & 1.73[0.71,4.26]\end{array}$

$\begin{array}{lllll}65 & 2.56518516 & 6.58017493 & 6.2 \% & 1.48[0.69,3.17]\end{array}$

$\begin{array}{lllll}159 & 3.50674478 & 19.21446712 & 18.0 \% & 1.20[0.77,1.88]\end{array}$

$\begin{array}{lllll}167 & 29.78 & 30.78 & 28.9 \% & 2.63[1.85,3.75]\end{array}$

1358

$100.0 \%$

$1.79[1.48,2.17]$

Two-year PFS

C. Two-year PFS HBAg seropositive HBsAg seronegative

Study or Subgroup HBSAg seropositive HBSAg seronegative Hazard Ratio Events Total Events Total $\quad 0-E$ Variance Weight $\operatorname{Exp}[(0-\mathrm{E}) / \mathrm{V}]$, Fixed, $95 \% \mathrm{Cl}$

Deng 2015

Guo 2015

Huang 2012

Shan 2016

$52 \quad 81 \quad 197$

$\begin{array}{llll}506 & 14.14987776 \quad 29.61820129 & 41.6 \%\end{array}$

$\begin{array}{rrrr}506 & 14.14987776 & 29.61820129 & 41.6 \% \\ 61 & 3.45586711 & 9.87026239 & 13.9 \%\end{array}$

$\begin{array}{llll}118 & 0.25672347 & 6.59069411 & 9.3 \%\end{array}$

$\begin{array}{llll}159 & 8.02613386 & 25.16360344 & 35.3 \%\end{array}$

Total $(95 \% \mathrm{Cl})$

39

$76 \quad 76$

844

$100.0 \%$

Total events $129 \quad 317$

Test for overall effect: $Z=3.07(P=0.002)$

$1.61[1.12,2.31]$
$1.42[0.76,2.65]$

$1.04[0.48,2.23]$

$1.38[0.93,2.03]$

$1.44[1.14,1.81]$

D. Five-year PFS

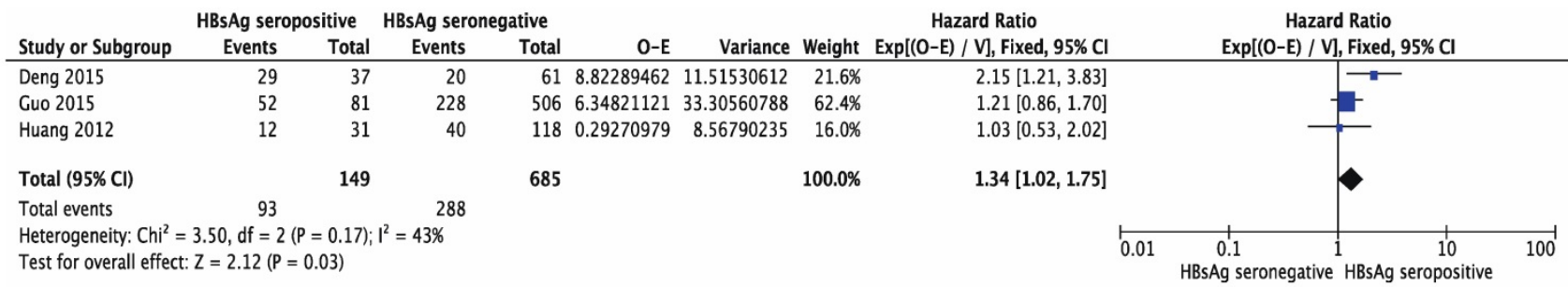

Figure 2. Forest plots comparing overall survival (OS) and progression-free survival (PFS) between $\mathrm{DLBCL}$ patients with chronically $\mathrm{HBs} A g$ seropositive and with $\mathrm{HBs} A \mathrm{~g}$ seronegative. (A) Two-year OS (HR 1.54, 95\% Cl 1.23-1.92, $P<0.001$ ); (B) Five-year OS (HR 1.79, 95\% Cl 1.48-2.17, $P<0.001$ ); (C) Two-year PFS (HR 1.44, 95\% Cl 1.41-1.81, $P=0.002)$; (D) Five-year PFS (HR $1.34,95 \%$ Cl 1.02-1.75, $P=0.03)$.

Table 3. Comparison clinical outcomes between DLBCL patients with and without HBsAg-seropositive

\begin{tabular}{|c|c|c|c|c|c|}
\hline Clinical factors & & Studies & Total & Effect Estimate & $\mathrm{p}$ value \\
\hline \multirow[t]{4}{*}{ Prognosis (figure 2) } & Two-year OS (A) & 7 & 1469 & $1.54[1.23,1.92]^{*}$ & $<0.001$ \\
\hline & Five-year OS (B) & 8 & 1756 & $1.79[1.48,2.17]^{*}$ & $<0.001$ \\
\hline & Two-year PFS (C) & 4 & 1069 & $1.44[1.14,1.81]^{*}$ & 0.002 \\
\hline & Five-year PFS (D) & 3 & 834 & $1.34[1.02,1.75]^{*}$ & 0.03 \\
\hline \multirow[t]{2}{*}{ Response to chemotherapy (figure 3) } & $\mathrm{CR}(\mathrm{A})$ & 10 & 2389 & $0.48[0.34,0.68]$ & $<0.001$ \\
\hline & $\mathrm{PD}(\mathrm{B})$ & 7 & 1986 & $2.08[1.34 .3 .24]$ & 0.001 \\
\hline \multirow[t]{7}{*}{ Clinical features (figure 4) } & Diagnosed Younger than 60 (A) & 10 & 2585 & $2.19[1.75,2.74]$ & $<0.001$ \\
\hline & Stage 3 or $4(B)$ & 12 & 3150 & $1.85[1.55,2.23]$ & $<0.001$ \\
\hline & LDH Level Elevation (C) & 9 & 2200 & $1.40[1.14,1.73]$ & 0.002 \\
\hline & B Symptoms (D) & 4 & 1159 & $1.31[0.71,2.42]$ & 0.39 \\
\hline & IPI Score over 2 & 8 & 2037 & $0.93[0.62,1.41]$ & 0.74 \\
\hline & Extra-nodal sites $\geq 2(\mathrm{~F})$ & 8 & 2028 & $1.13[0.88,1.44]$ & 0.34 \\
\hline & Non-GCB vs. GCB (G) & 5 & 1018 & $0.94[0.48,1.83]$ & 0.85 \\
\hline
\end{tabular}

* The result is estimated by Hazard ratio. 


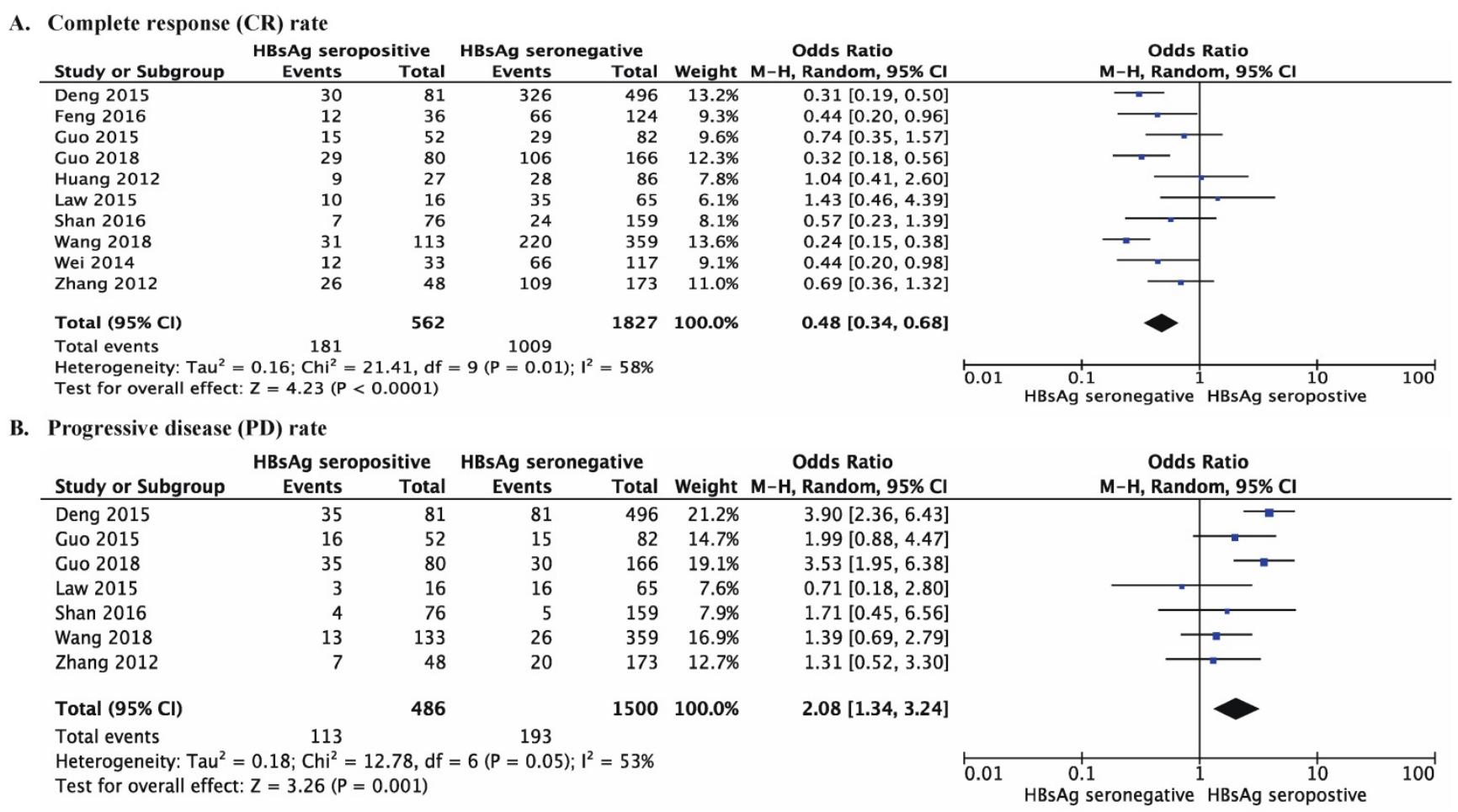

Figure 3. Forest plots comparing the response to primary chemotherapy for $\mathrm{DLBCL}$ patients with chronically $\mathrm{HBs} \mathrm{Ag}$ seropositive and with $\mathrm{HBs} \mathrm{Ag}$ seronegative. (A) Complete response (CR) rate (OR 0.48, 95\% Cl 0.34-0.68, $P<0.001)$; (B) Progressive disease (PD) rate $(\mathrm{OR} 2.08,95 \% \mathrm{Cl} 1.34-3.24, P=0.001)$.

Several systematic reviews have focused on the relationship between the incidence of DLBCL and HBV infection. And one most recent review, which was updated in March 2018, found patients with DLBCL had a higher risk of HBV infection than a control group of healthy individuals [23]. However, there is no evidence in support of an association between HBV infection and T cell NHL [24-27]. Therefore, we infer that $B$ cells may play a more important role in the pathogenesis of HBV-associated NHL than T cells. Moreover, compared to patients with HBV seronegative, DLBCL patients with HBV seropositive have a poorer prognosis, even after receiving anti-viral therapy to reduce the potential risk of $\mathrm{HBV}$ reactivation that may lead to liver dysfunction [2,3]. This observation may imply that HBV infection can negatively affect prognosis in DLBCL via processes that are not directly related to the risk of liver dysfunction and reactivation of hepatitis conferred by chemotherapy. Our data indicates that HBV may promote the progression of HBV-associated DLBCL via a number of other mechanisms beyond the direct effects of replication of the HBV virus. These findings provide a hint that HBV may possibly play a role in pathogenesis of DLBCL; however, unfortunately few studies have focused on this issue.

Although it is commonly assumed that the pathogenesis of HBV-associated DLBCL and $\mathrm{HCV}$-associated B cell NHL are similar, there are several differences between these diseases [28]. HBV, a typical hepadnavirus, has a remarkably unique viral pathogenesis compared to $\mathrm{HCV}$, a member of the family Flaviviridae. Even more intriguingly, unlike HBV infection and DLBCL, no associations have been reported between a poorer prognosis in HCV-associated B cell NHL after antiviral chemotherapy [24]. Therefore, we speculate that-unlike $\mathrm{HCV}$ infection-HBV infection may influence the incidence and progression of DLBCL in several ways.

Firstly, HBV infection may induce genetic changes in DLBCL. HBV DNA has been confirmed to integrate into the host genome, and HBV DNA has been detected in the tumor tissues of patients with DLBCL [2]. A recent study reported that some of the specific gene mutations observed in the tumor cells of HBV-associated DLBCL were regulated by BCL6 and FOXO1 [29]. This indicates that HBV-induced gene mutations may play a role in both the initiation and progression of DLBCL.

Secondly, Deng and colleagues found that in HBsAg-positive DLBCL patients, almost all amino acid sequences of heavy and light chain complementarity determining region 3 exhibited a high homology to antibodies specific for HBsAg. About $90 \%$ of IgHV and IgLV genes were mutated in these patients, which suggests that HBV-associated DLBCL may arise from HBV antigen-selected B cells [2]. 
A. Over 60-years-old

\begin{tabular}{lrrr} 
Study or Subgroup & $\begin{array}{r}\text { HBsAg seropositive } \\
\text { Events }\end{array}$ & $\begin{array}{r}\text { Total } \\
\text { HBsAg seron } \\
\text { Events }\end{array}$ \\
\hline Deng 2015 & 69 & 81 & 319 \\
Guo 2015 & 28 & 52 & 29 \\
Guo 2018 & 68 & 80 & 105 \\
Huang 2012 & 27 & 31 & 84 \\
Law 2015 & 13 & 16 & 40 \\
Shan 2016 & 49 & 76 & 89 \\
Wang 2018 & 36 & 52 & 120 \\
Wei 2014 & 37 & 59 & 137 \\
Zhang 2012 & 42 & 49 & 111 \\
Zheng 2014 & 48 & 56 & 217 \\
Total (95\% Cl) & & & \\
Total events & & 552 & \\
Heterogeneity: Chi ${ }^{2}=12.48, \mathrm{df}=9(\mathrm{P}=0.19) ;\left.\right|^{2}=28 \%$
\end{tabular}

Heterogeneity: $\mathrm{Chi}^{2}=12.48, \mathrm{df}=9(\mathrm{P}=0.19): \mathrm{I}^{2}=28 \%$

Test for overall effect: $Z=6.87(P<0.00001)$
Odds Ratio

Total Weight $\mathrm{M}-\mathrm{H}$, Fixed, 95\% C

$\begin{array}{lll}506 & 11.5 \% & 3.37[1.78,6.39]\end{array}$

$166 \quad 9.0 \% \quad 3.29[1.65,6.56]$

$118 \quad 4.0 \% \quad 2.73[0.89,8.40]$

$159 \quad 18.0 \% \quad 1.43[0.81,2.51]$

$200 \quad 13.4 \% \quad 1.50[0.78,2.88]$

$235 \quad 18.1 \% \quad 1.20[0.67,2.17]$

$173 \quad 6.2 \% \quad 3.35[1.42,7.91]$

$328 \quad 8.0 \% \quad 3.07[1.40,6.71]$

$2033 \quad 100.0 \% \quad 2.19[1.75,2.74]$
$83 \quad 9.1 \% \quad 2.17[1.07,4.41]$

$\begin{array}{lll}65 & 2.6 \% & 2.71[0.70,10.46]\end{array}$

Odds Ratio

M-H, Fixed, 95\% Cl

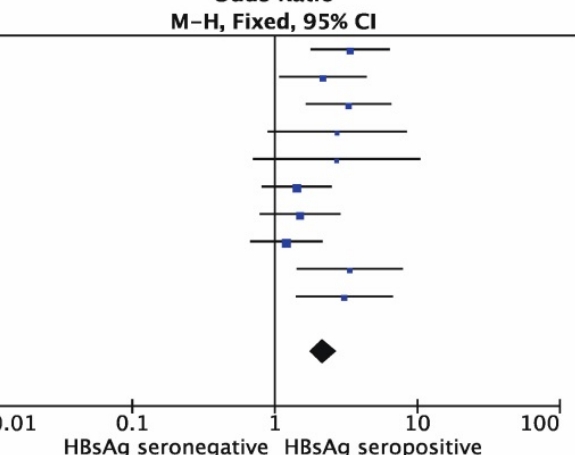

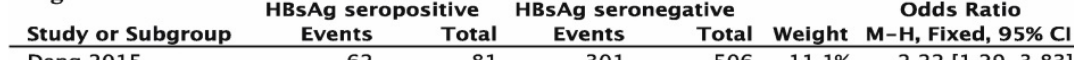
\begin{tabular}{lllllll}
\hline Deng 2015 & 62 & 81 & 301 & 506 & $11.1 \%$ & $2.22[1.29,3.83]$
\end{tabular}

Feng 2016

Guo 2015

Guo 2018

Huang 2012

Law 2015

Shan 2016

Wang 2018

Wei 2014

Wei 2015

Zhang 2012

Zheng 2014

Total (95\% CI)

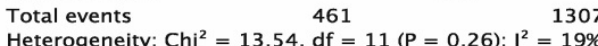

Test for overall effect: $Z=6.63(P<0.00001)$

C. Elevated LDH

\begin{tabular}{lrrr} 
Study or Subgroup & $\begin{array}{r}\text { HBsAg seropositive } \\
\text { Events }\end{array}$ & $\begin{array}{r}\text { Total } \\
\text { HBsAg seron } \\
\text { Events }\end{array}$ \\
\hline Deng 2015 & 47 & 81 & 205 \\
Feng 2016 & 15 & 36 & 60 \\
Guo 2015 & 24 & 52 & 28 \\
Guo 2018 & 45 & 80 & 67 \\
Law 2015 & 12 & 16 & 50 \\
Shan 2016 & 34 & 76 & 65 \\
Wei 2015 & 12 & 33 & 55 \\
Zhang 2012 & 19 & 49 & 53 \\
Zheng 2014 & 23 & 56 & 105 \\
& & & \\
Total (95\% Cl) & & 479 & \\
Total events & 231 & & 688 \\
Heterogeneity: Chi ${ }^{2}=10.91, \mathrm{df}=8(\mathrm{P}=0.21) ; \mathrm{I}^{2}=27 \%$ \\
Test for overall effect: $\mathrm{Z}=3.15(\mathrm{P}=0.002)$
\end{tabular}

D. B symptoms

\begin{tabular}{|c|c|c|c|c|c|}
\hline \multirow[b]{2}{*}{ Study or Subgroup } & \multicolumn{2}{|c|}{ HBsAg seropositive } & \multicolumn{2}{|c|}{ HBsAg seronegative } & \multirow[b]{2}{*}{ Weight } \\
\hline & Events & Total & Events & Total & \\
\hline Deng 2015 & 47 & 81 & 183 & 506 & $29.4 \%$ \\
\hline Guo 2018 & 26 & 90 & 60 & 166 & $27.7 \%$ \\
\hline Law 2015 & 9 & 16 & 37 & 65 & $16.6 \%$ \\
\hline Shan 2016 & 23 & 76 & 36 & 159 & $26.3 \%$ \\
\hline Total $(95 \% \mathrm{Cl})$ & & 263 & & 896 & $100.0 \%$ \\
\hline $\begin{array}{l}\text { Total events } \\
\text { Heterogeneity: Tau } \\
\text { Test for overall effec }\end{array}$ & $\begin{array}{r}105 \\
0.28 ; \mathrm{Chi}^{2} \\
\mathrm{Z}=0.86(\mathrm{P}\end{array}$ & $\begin{array}{l}23, \mathrm{df}= \\
39)\end{array}$ & $\begin{array}{r}316 \\
=3(P=0.01\end{array}$ & $=73 \%$ & \\
\hline
\end{tabular}

E. IPI score

\begin{tabular}{|c|c|c|c|c|c|}
\hline \multirow[b]{2}{*}{ Study or Subgroup } & \multicolumn{2}{|c|}{ HBsAg seropositive } & \multicolumn{2}{|c|}{ HBsAg seronegative } & \multirow[b]{2}{*}{ Weight } \\
\hline & Events & Total & Events & Total & \\
\hline Deng 2015 & 34 & 81 & 155 & 506 & $16.4 \%$ \\
\hline Feng 2016 & 10 & 36 & 56 & 124 & $11.6 \%$ \\
\hline Guo 2015 & 20 & 52 & 21 & 83 & $12.4 \%$ \\
\hline Guo 2018 & 32 & 80 & 50 & 166 & $15.2 \%$ \\
\hline Law 2015 & 2 & 16 & 23 & 65 & $5.2 \%$ \\
\hline Wei 2014 & 9 & 33 & 51 & 117 & $11.1 \%$ \\
\hline Wei 2015 & 28 & 59 & 114 & 235 & $15.0 \%$ \\
\hline Zheng 2014 & 12 & 56 & 92 & 328 & $13.3 \%$ \\
\hline Total $(95 \% \mathrm{Cl})$ & & 413 & & 1624 & $100.0 \%$ \\
\hline $\begin{array}{l}\text { Total events } \\
\text { Heterogeneity: Tau } \\
\text { Test for overall effe }\end{array}$ & $\begin{array}{r}147 \\
0.21 ; \mathrm{Chi}^{2}\end{array}$ & $3, \mathrm{df}$ & $\begin{array}{r}562 \\
7(P=0.0\end{array}$ & $=63 \%$ & \\
\hline
\end{tabular}

Odds Ratio

Odds Ratio

$3.39[1.43,8.02]$

$2.46[1.11,5.46]$

$2.17[1.19,3.96]$

$1.20[0.54,2.68]$

$1.10[0.63,1.90]$

$1.88[1.24,2.84]$

$1.61[0.86,3.03]$

$3.91[1.57,9.71]$

$2.44[1.21,4.91]$

$2.44[1.21,4.91]$
$1.39[0.77,2.49]$

1.85 [1.55, 2.23]
$0.91[0.29,2.83]$

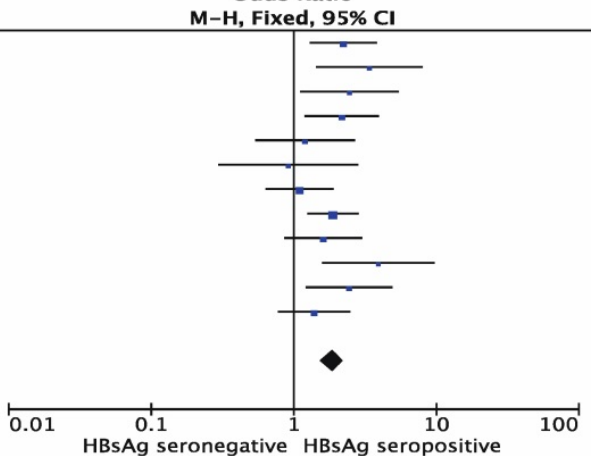

Odds Ratio

Odds Ratio

Total Weight $\mathrm{M}-\mathrm{H}$, Fixed, 95\% Cl

M-H, Fixed, 95\% C

$506-16.3 \%-2.03[1.26,3.27]$

$124 \quad 10.8 \% \quad 0.76[0.36,1.61]$

$\begin{array}{rrr}83 & 7.9 \% & 1.68[0.83,3.43] \\ 166 & 13.0 \% & 1.90[1.11,3.26]\end{array}$

$65 \quad 3.4 \% \quad 0.90[0.25,3.21]$

$159 \quad 15.9 \% \quad 1.17[0.67,2.03]$

$117 \quad 10.5 \% \quad 0.64[0.29,1.43]$

$9.8 \%-1.43[0.74,2.77]$

$1.48[0.83,2.65]$

$1721 \quad 100.0 \% \quad 1.40[1.14,1.73]$

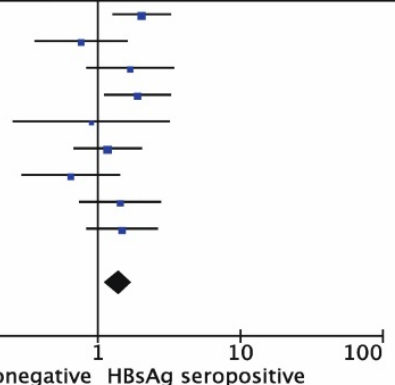

Odds Ratio

, Random, 95\% Cl

$2.44[1.51,3.93]$

$0.72[0.41,1.25]$

$0.97[0.32,2.93]$

$1.48[0.80,2.74]$

$1.31[0.71,2.42]$

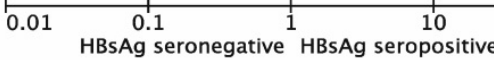

Odds Ratio

M-H, Random, 95\% Cl

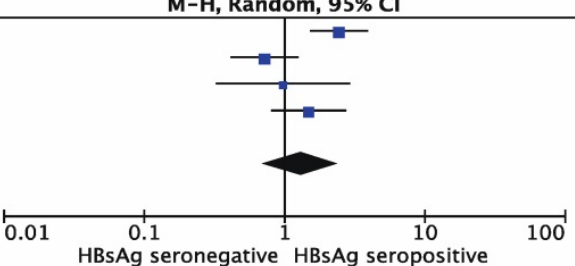

Odds Ratio

, Random, 95\% Cl

Odds Ratio

$1.85[0.87,3.89]$

$1.55[0.89,2.70]$

$0.26[0.05,1.25]$

$0.49[0.21,1.13]$

$0.96[0.54,1.70]$

$0.70[0.35,1.38]$

$0.93[0.62,1.41]$

M-H, Random, 95\% C

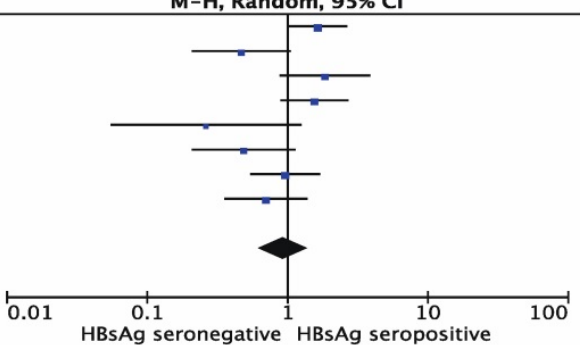


F. Extra-nodal metastasis

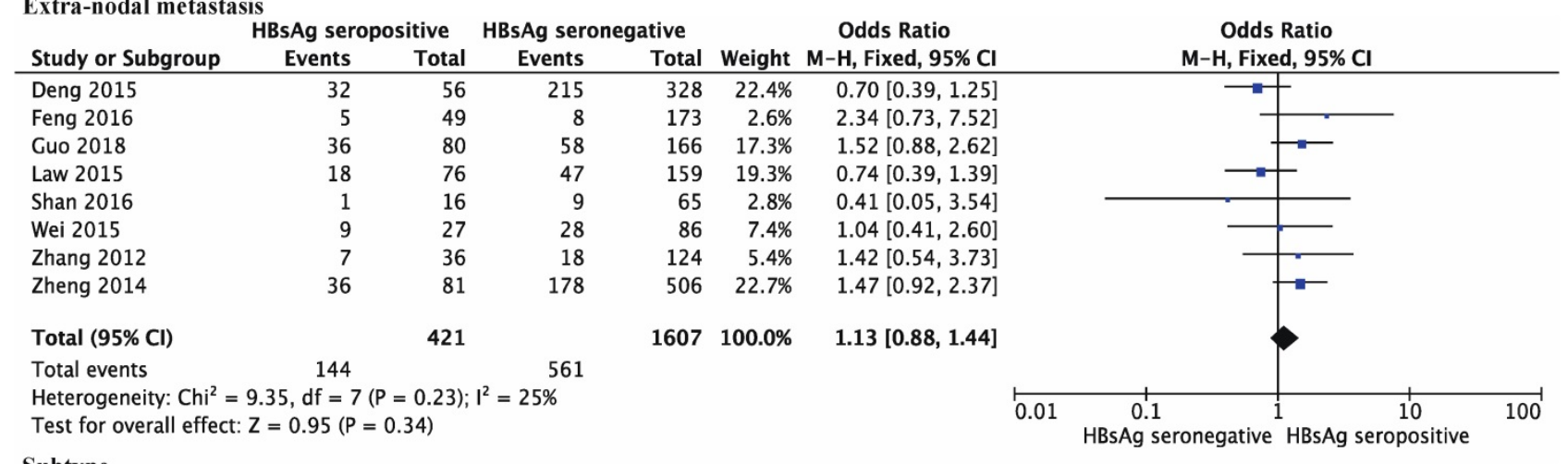

G. Subtype

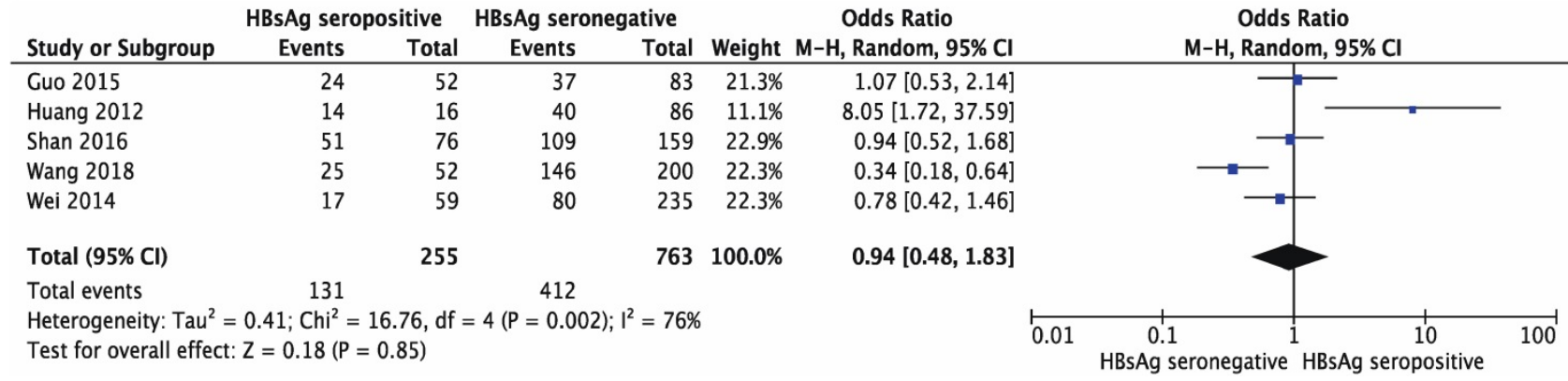

Figure 4. Forest plots comparing the clinical features of DLBCL patients with chronically HBsAg seropositive and with $\mathrm{HBsAg}$ seronegative. (A) Age of onset of DLBCL, over 60 -years-old (OR 2.19, $95 \% \mathrm{Cl} 1.75-2.74 ; P<0.001)$. (B) Disease stage at diagnosis, stage 3 or 4 (OR $1.85,95 \% \mathrm{Cl} 1.55-2.23 ; P<0.001)$. (C) Elevated LDH (OR 1.40, 95\% Cl 1.14-1.73, $P=0.002$ ). (D) Presence of $B$ symptoms (OR 1.31, 95\% Cl 0.71-2.24, $P=0.39)$. (E) IPI score, 2 or higher (OR 0.93, 95\% $C l 0.62-1.41, P=0.74)$. (F) More than two sites of extra-nodal metastasis (OR 1.13, 95\% Cl 0.88-1.44, $P=0.34)$. (G) Subtype of DLBCL, non-GCB (OR 0.94, 95\% Cl 0.48-1.83, $P=0.85$ ).

This finding suggests that long-term antigenic stimulation caused by chronic HBV infection could contribute to the initiation of DLBCL. The inference is supported by two findings: firstly, an increased risk of B-NHL is not observed among individuals who had been infected with or vaccinated against $\operatorname{HBV}[7,30$, 31]. Secondly, HBsAg and $\mathrm{HBcAg}$ can be detected in the tumor tissues of patients with DLBCL and chronic $\mathrm{HBV}$ infection. It is hard to achieve serological conversion of $\mathrm{HBsAg}$ in most cases, even after administering effective anti-viral therapy against HBV. The antigen-stimulation hypothesis may explain why patients with DLBCL and HBV infection have a poorer prognosis, even after receiving anti-viral therapy. Long-term presentation of HBsAg in the serum of patients with chronic HBV infection may lead to immune tolerance and may thus worsen the prognosis of DLBCL [32-34]. Moreover, the HBsAg titer may also play a decisive role in the interplay between the virus and immune system. Therefore, we recommend that quantitative measurement of serum HBsAg is necessary for HBV-infected patients with DLBCL in future studies. The introduction of immunomodulatory strategies, which may break the immune tolerance induced by HBsAg, may possibly boost the response of DLBCL to chemotherapy and improve prognosis in patients with chronic HBV infection. However, the specific mechanisms by which HBV induces the initiation and promotes the progression of DLBCL remain unknown and need further investigation.

There are some limitations to this meta-analysis. Firstly, publication bias may exist as only published trials were included (Figure S1); it is not known whether related unpublished trials exist. Secondly, 10 of the all the included clinical trials, which focused on the prognosis of $\mathrm{HBV}$-associated DLBCL, were case-control studies. Thirdly, all of the related clinical trials were conducted in regions where the prevalence of HBV is high. Thus, all of these factors may bias the systematic review.

In conclusion, this meta-analysis is the first demonstration that chronic HBV infection leads to poorer outcomes and a poorer prognosis in DLBCL. This study suggests that in addition to anti-viral therapy, more attention should be paid to the virological effects of $\mathrm{HBV}$, especially $\mathrm{HBsAg}$, during the progression of DLBCL.

\section{Abbreviations}

CR: complete response; DLBCL: diffuse large B-cell lymphoma; HBV: hepatitis B virus; HBsAg: HBV surface antigen; HCC: hepatocellular carcinoma; HR: Hazard ratios; IPI: International Prognostic Index; LDH: lactate dehydrogenase; MOOSE: Meta-Analysis of Observational Studies in Epidemiology; NHL: non-Hodgkin lymphoma; NOS: 
the Newcastle-Ottawa Scale; OS: overall survival; PD: progressive disease; PFS: Progressions free survival.

\section{Supplementary Material}

Supplementary figure and table.

http://www.jcancer.org/v10p3450s1.pdf

\section{Acknowledgements}

This study was funded by grants from the Chinese National Key Project Specialized for Infectious Diseases (2018ZX10301208-001-003) and the National Natural Science Foundation of China (81370046). Dr C Zhao was supported by grants from the Fok Ying Tung Education Foundation (142016) of the Chinese Ministry of Education and the Outstanding Talent Plan (2015) of Fudan University.

\section{Author Contribution}

$\mathrm{CZ}$ and HJW designed and supervised the work, and analyzed and interpreted the data; XYR, HJW and CZ wrote the manuscript; XYR, HW and JXM performed the literature search, data extraction, and data and statistical analysis; XYR, HW, SJ, SKP, YS and LCW performed the quality assessment; all authors read and approved the final manuscript.

\section{Competing Interests}

The authors have declared that no competing interest exists.

\section{References}

1. Swerdlow SH, Campo E, Harris NL, Jaffe ES, Pileri SA, Stein H, et al. WHO classification of tumors of haematopoietic and lymphoid tissues. 4th edition. Lyon, France: IARC; 2017.

2. Deng L, Song $\mathrm{Y}$, Young $\mathrm{KH}, \mathrm{Hu} \mathrm{S}$, Ding $\mathrm{N}$, Song $\mathrm{W}$, et al. Hepatitis B virus-associated diffuse large B-cell lymphoma: unique clinical features, poor outcome, and hepatitis B surface antigen-driven origin. Oncotarget. 2015; 6: 25061-73.

3. Guo W, Zhang W, Liu C, Song Y, Bai O. Clinical Analysis of the HBV Infection Status of 135 Patients with Diffuse Large B Cell Lymphoma Treated with R-CHOP or CHOP/CHOP-Like Chemotherapy. Plos One. 2015; 10: e0129064.

4. Shan L, Teng S, Wang H. Clinical features and prognosis of HBsAg-positive patients with diffuse large B-cell lymphoma. Journal of Practical Oncology. 2016; 31: 163-9.

5. Law MF, Lai HK, Chan HN, Ha CY, Ng C, Yeung YM, et al. The impact of hepatitis $B$ virus (HBV) infection on clinical outcomes of patients with diffuse large B-cell lymphoma. European Journal of Cancer Care. 2015; 24: 117-24.

6. Zhang $Y$. The relationship between hepatitis B Virus infection and diffuse large B cell lymphoma. Zhejiang University. 2012.

7. Huang CE, Yang YH, Chen YY, Chang JJ, Chen KJ, Lu CH, et al. The impact of hepatitis $\mathrm{B}$ virus infection and vaccination on the development of non-Hodgkin lymphoma. Journal of Viral Hepatitis. 2017; 24: 885-94.

8. Wei Z, Wang ZM, Zou SH. The impact of hepatitis B virus concurrent infection on peripheral $\mathrm{T}$ cells in diffuse large $\mathrm{B}$ cell lymphoma patients. China Oncology. 2014; 24: 765-9.

9. Feng $Y$, Wang X, Liu XY, Hu DH, Yang C. Relationship of HBV infection and diffuse large B cell lymphoma. Chinese Journal of Nosocomiology. 2016; 26: 2887-9.

10. Liu J, Zhang S, Wang Q, Shen H, Zhang M, Zhang Y, et al. Seroepidemiology of hepatitis $B$ virus infection in 2 million men aged 21-49 years in rural China: a population-based, cross-sectional study. The Lancet Infectious diseases. 2016; 16: 80-6.

11. Cheson BD, Pfistner B, Juweid ME, Gascoyne RD, Specht L, Horning SJ, et al. Revised response criteria for malignant lymphoma. Journal of Clinical Oncology. 2007; 25: 579-86.

12. [Internet] Wells $\mathrm{G}$, Shea B, O'Connell D, Peterson J, Welch V, Losos M, et al. The Newcastle-Ottawa Scale (NOS) for assessing the quality of $\begin{array}{lll}\text { nonrandomised } & \text { studies } & \end{array}$ http://www.ohri.ca/programs/clinical_epidemiology/oxford.asp

13. Stroup DF, Berlin JA, Morton SC, Olkin I, Williamson GD, Rennie D, et al. Meta-analysis of observational studies in epidemiology: a proposal for reporting. Meta-analysis Of Observational Studies in Epidemiology (MOOSE) group. Journal of the American Medical Association. 2000; 283: 2008-12.

14. Chai XF, Liu MG, Sun MM. Clinicopathologic relationship between hepatitis B virus infection and diffuse large B cell lymphoma. China Practical Medicine. 2016; 11: 3-4

15. Fang Y, Wang L, Qian Y, Zhao WL. Efficacy and prognostic analysis of relapsed/refractory diffuse large B-cell lymphoma patients with hepatitis B virus infection. Zhonghua Xue Ye Xue Za Zhi. 2018; 39; 1017-20

16. Huang Y, Yang S, Shi Y, Yang J, Zhang C, Qin Y, et al. Clinical characteristics and prognostic analysis of diffuse large B-cell lymphoma patients with HBV infection. Oncology Progress. 2012; 10: 289-95.

17. Shan L, Song T, Wang H, Chen H, Li S. Clinical features and prognosis of HBsAg-positive patients with diffuse large B-cell lymphoma. Journal of Practical Oncology. 2016; 31: 163-9.

18. Wang Q, Li J, Ni R, Dai J, Guo L, Yan Y. Correlation study of hepatitis B virus infection and diffuse large B-cell lymphoma. International Journal of Virology. 2016; 23: 332-5.

19. Wei H, Luo C, Liu K, Zhong X, Lu Y, Huang Y, et al. The relevance of HBV infection to clinic pathological characteristics and prognosis of diffused large B-cell lymphoma. . Chinese Journal of Gerontology. 2015: 2455-7.

20. Zhang Y, Li M, Deng F, Chen S, Zhang J. Analysis on hepatitis B virus rate in patients with non-Hodgkin lymphoma. Laboratory Medicine and Clinic. 2015: 3348-50.

21. Wang Y, Wang $\mathrm{H}$, Pan $\mathrm{S}, \mathrm{Hu} \mathrm{T}$, Shen J, Zheng H, et al. Capable Infection of Hepatitis B Virus in Diffuse Large B-cell Lymphoma. Journal of Cancer. 2018; 9: 1575-81.

22. Guo YF, Pan JX, Zhuang WH. Concurrent and reactivation of hepatitis B virus infection in diffuse large B-cell lymphoma: risk factors and survival outcome. Infectious Agents and Cancer. 2018; 13: 40

23. Li M, Gan Y, Fan C, Yuan H, Zhang X, Shen Y, et al. Hepatitis B virus and risk of non-Hodgkin lymphoma: An updated meta-analysis of 58 studies. Journal of Viral Hepatitis. 2018; 25: 894-903.

24. Dalia S, Chavez J, Castillo JJ, Sokol L. Hepatitis B infection increases the risk of non-Hodgkin lymphoma: a meta-analysis of observational studies. Leukemia Research. 2013; 37: 1107-15.

25. Nath A, Agarwal R, Malhotra P, Varma S. Prevalence of hepatitis B virus infection in non-Hodgkin lymphoma: a systematic review and meta-analysis. Internal Medicine Journal. 2010; 40: 633-41.

26. Qi Z, Wang H, Gao G. Association of risk of non-Hodgkin's lymphoma with hepatitis B virus infection: a meta-analysis. International journal of clinical and experimental medicine. 2015; 8: 22167-74.

27. Yi HZ, Chen JJ, Cen H, Yan W, Tan XH. Association between infection of hepatitis B virus and onset risk of B-cell non-Hodgkin's lymphoma: a systematic review and a meta-analysis. Medical Oncology. 2014; 31: 84.

28. Matsuo K, Kusano A, Sugumar A, Nakamura S, Tajima K, Mueller NE. Effect of hepatitis $C$ virus infection on the risk of non-Hodgkin's lymphoma: a meta-analysis of epidemiological studies. Cancer Science. 2004; 95: 745-52.

29. Ren W, Ye X, Su H, Li W, Liu D, Pirmoradian M, et al. Genetic landscape of hepatitis B virus-associated diffuse large B-cell lymphoma. Blood. 2018; 131: 2670-81.

30. Becker N, Schnitzler P, Boffetta P, Brennan P, Foretova L, Maynadie M, et al. Hepatitis $\mathrm{B}$ virus infection and risk of lymphoma: results of a serological analysis within the European case-control study Epilymph. Journal of Cancer Research and Clinical Oncology. 2012; 138: 1993-2001.

31. Taborelli M, Polesel J, Montella M, Libra M, Tedeschi R, Battiston M, et al. Hepatitis B and C viruses and risk of non-Hodgkin lymphoma: a case-control study in Italy. Infectious Agents and Cancer. 2016; 11: 27-32

32. Lampertico P, Maini M, Papatheodoridis G. Optimal management of hepatitis B virus infection - EASL Special Conference. Journal of Hepatology. 2015; 63: 1238-53.

33. Liaw YF, Jia JD, Chan HL, Han KH, Tanwandee T, Chuang WL, et al. Shorter durations and lower doses of peginterferon alfa-2a are associated with inferior hepatitis B e antigen seroconversion rates in hepatitis B virus genotypes B or C. Hepatology. 2011; 54: 1591-9.

34. Sonneveld MJ, Hansen BE, Piratvisuth T, Jia JD, Zeuzem S, Gane E, et al. Response-guided peginterferon therapy in hepatitis $\mathrm{B}$ e antigen-positive chronic hepatitis B using serum hepatitis B surface antigen levels. Hepatology, 2013: $58: 872-80$ 